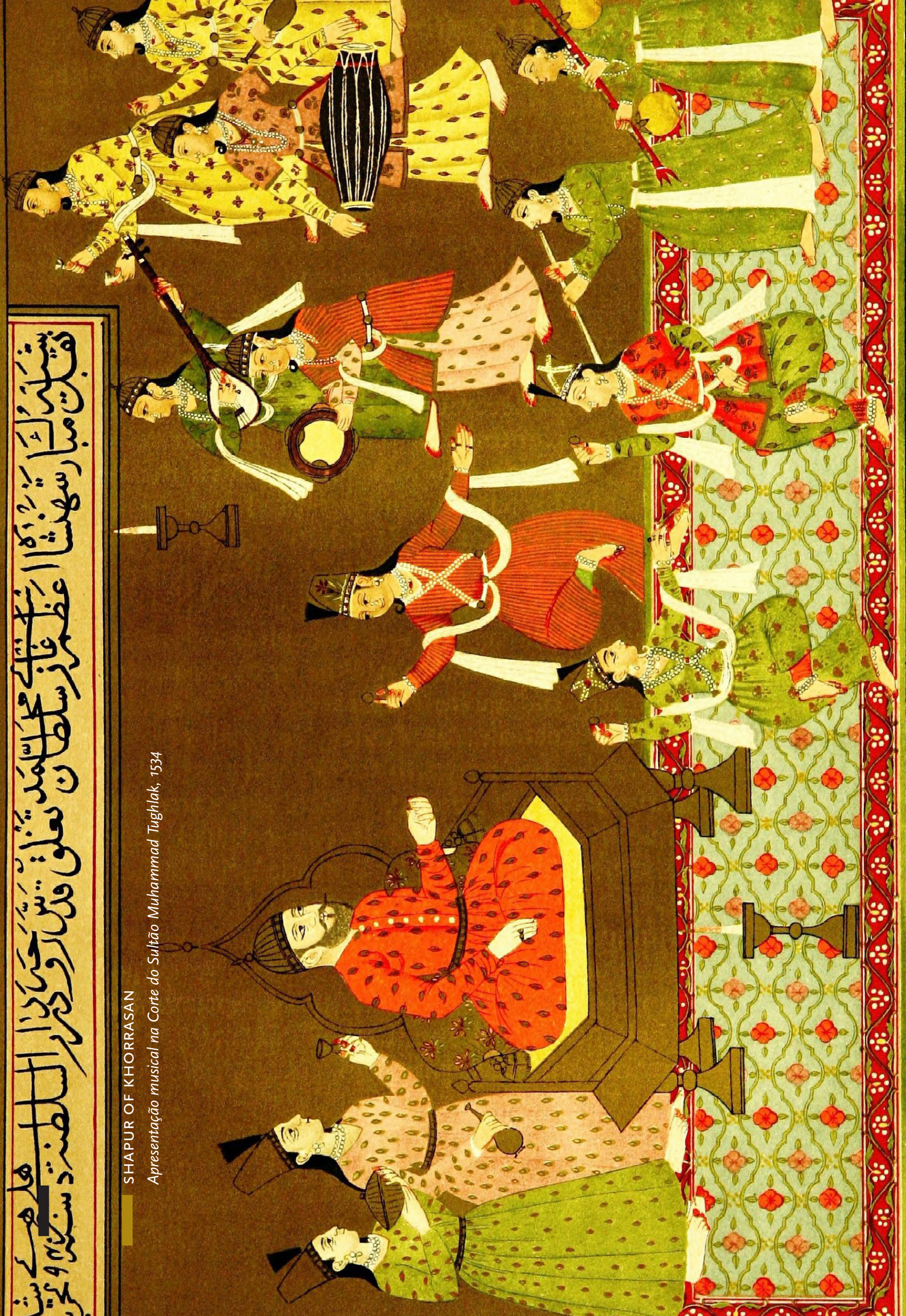




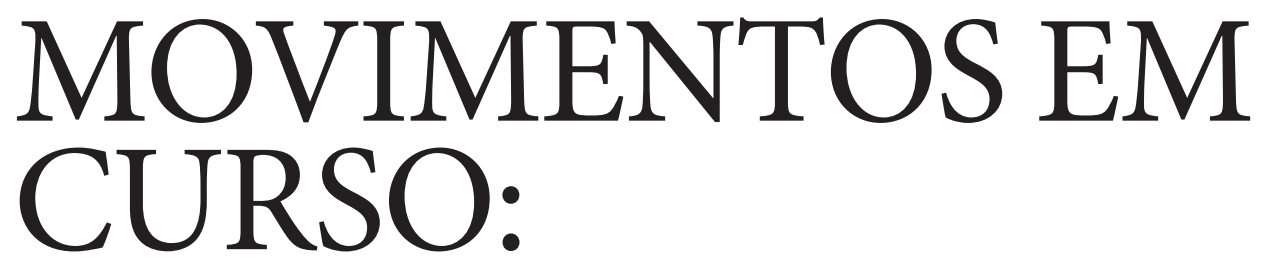

\section{questões da dança no século da invenção teórica do corpo}

\section{GRAZIELA ANDRADE *}

RESUMO No século XX, o corpo experimentou as mais velozes transformações que uma centena de anos já lhe trouxe e, nesse contexto, o pensamento e o movimento da dança alteraram-se consideravelmente. Em um breve recorte histórico que parte do século anterior, investigamos e apresentamos alguns personagens e concepções relevantes, para compreendermos a "herança" recebida pelo Campo da Dança.

PalaVras-chave Movimento. Dança. Corpo.

\section{MOVEMENTS IN PROGRESS:}

\section{dance issues in the century of the theoretical invention of the body}

ABSTRACT In the $19^{\text {th }}$ century, the body experienced the fastest transformations that a hundred years have ever brought to it, and in this context, thought and dance movement have changed considerably. In a brief historical period beginning in the previous century, we investigate and point out some characters and concepts relevant to the understanding of the "inheritance" received by the field of dance.

KEYWORDS Movement. Dance. Body..

* Artista da dança e Professora Adjunta do curso de Licenciatura em Dança da Escola de Belas Artes da Universidade Federal de Minas Gerais.

E-mail: graandrade@gmail.com.

Recebido em 31/5/2015. Aprovado em 27/3/2016 


\section{Uma questão de percepção}

Na virada do século XIX, a americana Marie Louise Fuller ou, simplesmente, Loïe Fuller (I862-I928) como se tornou conhecida, fascinou a classe artística europeia com suas tempestades de tecido e luz, que se tornaram marco do nascimento de uma nova e ainda incompreendida abstração do corpo. Essa revelação do inesperado impeliu e antecedeu o questionamento sobre a experiência sensorial que iria modificar profundamente o movimento, a expressão e, igualmente, o status do corpo na dança que estava por vir.

Em suas apresentações, a artista realizava uma trama entre tecidos, espelhos e projetores luminosos que geravam efeitos espetaculares, até então desconhecidos. Em cena, integrados aos seus vestidos, estavam véus e bastões com os quais ela provocava um prolongamento do corpo e causava uma ampliação do movimento produzido. Por vezes, o esvoaçante conjunto de véus em deslocamento, sugeria um momentâneo desaparecimento do corpo em meio ao mar de tecidos e luzes em que sua dança estava mergulhada. Essa foi a grande descoberta e o princípio norteador de toda a obra da americana que ganhou a atenção, principalmente dos franceses em mágicas composições tais como: Danse Serpentine, Danse du Feu e Danse du Papillon.

Para a historiadora da dança Annie Suquet (2006), Loïe Fuller, em sua fantasmagoria luminosa sem precedentes, inicia e abre espaço para uma sondagem sobre as propriedades do movimento. Logo, os mesmos tecidos que acobertavam o corpo intentavam desvelar a trajetória do gesto, em um esforço de se fazer visível a própria mobilidade que, uma vez desenhada pelo corpo, efemeramente desaparecia. Não gratuitamente, a artista transformara-se em um acontecimento. Suas aparições tocaram em pontos-chave do pensamento do corpo que seriam investigados dali em diante. Como resume Suquet:

Com Loïe Fuller emerge a ideia do corpo dançante como um corpo vibrátil, confluente de dinâmicas sutis, mas esta concepção tão capital para o futuro da dança no século XX emaranha-se, por assim dizer, nas dobras da experiência da visão,experiência essa que 
conhecerá uma profunda revalorização no século XX. A percepção do corpo e, mais precisamente do corpo em movimento, será profundamente modificada (Suquet, 2006, p.409, tradução nossa) $)^{\mathrm{T}}$.

A artista é, portanto, historicamente marcante para a dança, pois pontua uma espécie de virada perceptiva, reunindo, em referência ao corpo, problematizações, metáforas e apostas para as quais inúmeros olhares se dirigiriam na entrada do século XX, que, como quer Courtine (2006), foi aquele da invenção teórica do corpo. Antes disso, o corpo era compreendido apenas como uma parte da matéria. Nesse século, o corpo experimentaria as maiores e mais velozes transformações que uma centena de anos já lhe trouxe.

Investigando algumas dessas mutações do corpo, do movimento e do pensamento - tendo o campo da dança como referência -, curiosamente, alcançamos as interpelações de um músico, orador e teórico autodidata, que é anterior a Loïe Fuller. Trata-se do francês François Delsarte (I8II-I87I) que, interessado na compreensão e no desenvolvimento de um esquema que indicasse associações entre os gestos e emoções humanas, acaba tendo sua obra apropriada pela dança moderna, influenciando assim toda uma geração de artistas ao longo do século.

Antes de descrevermos as concepções e influências de Delsarte, vejamos, na figura abaixo, uma linha histórica que nos guiará nas citações sobre alguns nomes relevantes para o surgimento da dança moderna, bem como na indicação das datas de nascimento e morte desses personagens.

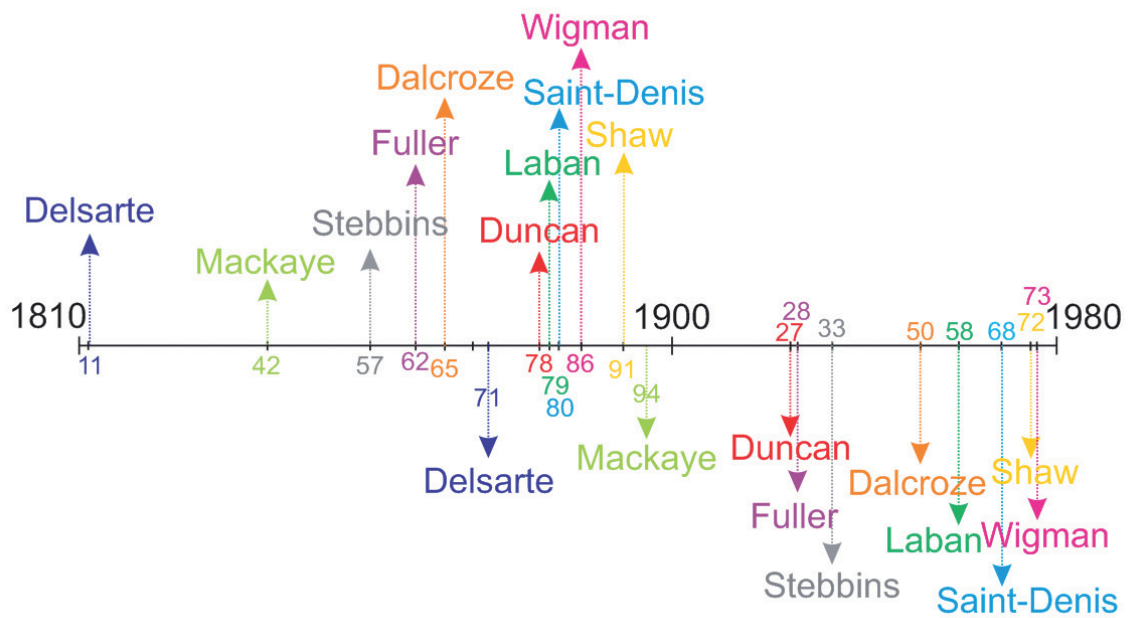

Figura o1 - Linha Histórica da Dança ${ }^{2}$. Vida e morte dos principais personagens citados.

Fonte: Elaborado pela autora
1 Avec Loïe Fuller émerge I'idée du corps dansant comme corps vibratile, confluent de dynamiques subtiles, mais cette

conception, si capitale pour l'avenir de la danse au XXffi siècle, se love pour ainsi dire dans les replis de l'expérience de la vision. Celle-ci connaît une profonde réévaluation au XIXffi siècle. La perception du corps, et plus précisément du corps en mouvement, s'en trouvera fondamentalement modifiée (Suquet, 2006, p.409)
2 No desenho, as proporções entre as datas são apenas aproximativas, uma vez que foram livremente traçadas sem o auxílio de um programa especializado. 
3 Henrietta Hovey (1849-1918) foi a principal representante da terceira geração do delsartismo americano. Como François Delsarte jamais esteve nos EUA, seu aluno e discípulo Steeve Mckaye foi o maior responsável pela divulgação de seu trabalho no país. Hovey conheceu o sistema seguindo cursos de Mckaye e, no fim dos anos de 1870, ela foi aluna, em Paris, de Gustave Delsarte, filho de François Delsarte.

4 A propósito desta obra, vale ressaltar que, embora ela contribua, consideravelmente, com a apresentação de novas perspectivas sobre a história contemporânea do corpo e da dança, ela apresenta questões que escapam ao viés científico, como nos lembra, na intro-

dução do mesmo livro, a historiadora da dança Annie

Suquet (2005). Para ela,

Ted Shawn não escondia seu forte desejo de fazer de François Delsarte o fundador da dança moderna americana e, com isso, ele tende a atenuar as influências da dança alemã e as de Rudolf Von Laban, que seria outro candidato ao posto de "pai da dança moderna".

5 Le geste est plus que la parole. Ce n'est pas ce que nous disons qui persuade mais la manière dont nous

le disons. La parole est inférieure au geste parce qu'elle correspond au phénomène de l'esprit. Le geste est I'agent du cœur, l'agent de la persuasion.

\section{O Delsartismo}

Como que por intuição científica, Delsarte iniciou seus estudos pela observação. Seguidor convicto e divulgador do que viria a se tornar o "delsartismo", o bailarino americano Ted Shawn (I89I-I972), que conhecera o sistema de Delsarte por meio de Henrieta Hovey3, publica em I954 o livro "Every Little Movement: a Book about François Delsarte". Na tradução francesa de 2005 "Chaque Petit Mouvement: à propos de François Delsarte"4 à qual tivemos acesso, o autor relata que Delsarte passou anos de sua vida recolhendo um grande número de dados que versavam sobre a maneira como seres humanos de todas as idades, origens sociais e temperamentos reagiam a estímulos emocionais.

Para tanto, segundo as descrições de Shawn (2005), Delsarte esteve observando distintos e variados grupos de pessoas e, em certa ocasião, chegou a acompanhar o resgate de trabalhadores que haviam sido soterrados em uma mineradora. Nessa tragédia, apreendeu e registrou atitudes, gestos, timbres de voz e entonações; tanto da equipe de socorro quanto daqueles que esperavam por notícias na superfície, buscando assim avaliar o retrato físico das incertezas, medo, esperança, felicidade e dor dos envolvidos no drama.

Segundo Azevedo (2009), dados de situações como essa foram recolhidos durante cerca de 40 anos, e o tratamento desses dados fez de Delsarte um pioneiro na análise aprimorada dos gestos e expressões humanas. Para ele, o gesto vai além do discurso, pois corresponde e revela uma emoção antes mesmo do pensamento. Em suas próprias palavras:

O gesto é mais que a palavra. Não é o que nós dizemos que persuade, mas a maneira como nós dizemos. A palavra é inferior ao gesto porque ela corresponde ao fenômeno do espírito. O gesto é o agente do coração, agente da persuasão. O que demanda um volume é expresso por um só gesto. Cem páginas não dizem o que um simples movimento pode exprimir, porque um simples movimento exprime nosso ser por inteiro (Delsarte apud Shaw, 2005, p. 72, tradução nossa)5.

Essa crença absoluta na potência dos gestos, entendido como ação capaz de revelar nossa própria interioridade, impulsionou Delsarte a desenvolver seu sistema que iria gerar o "corolário-chave da dança moderna: a intensidade do sentimento comanda a intensidade do gesto (Bourcier, 200I, p.I44)". De fato, nos esforços de compreensão de 
Delsarte, parece haver uma busca pela conjunção entre "dentro e fora”, corpo e alma, o que pode ser demonstrado pelas duas leis que fundamentam todo seu sistema: a da correspondência e a da trindade. A primeira lei afirmará que a cada função espiritual corresponde uma função do corpo e, reciprocamente, também as funções corporais teriam um ato espiritual como correspondente. Assim, ainda que um gesto seja executado por uma função muscular e esteja associado à respiração, ele sempre terá o suporte de uma emoção, sentimento ou ideia.

Por sua vez, o princípio da trindade é para Delsarte a constatação universal de uma espécie de fórmula que estaria presente no próprio ser e poderia ser replicada em inúmeros fenômenos. Com essa afirmação, ele justifica a relevância que essa formação recebe em seu sistema e revela a óbvia inspiração cristã (pai, filho e espírito santo), inerente às suas concepções. Em extratos encontrados de seus cursos de Estética Aplicada ${ }^{6}$, ministrados entre I850-60, podemos ler a seguinte explicação sobre a formação de trindades:

O princípio de meu sistema repousa sobre a constatação de que há no mundo uma fórmula universal que se aplica a todas as ciências, a todas as coisas possíveis. Essa fórmula é a trindade. O que é preciso para se formar uma trindade? É preciso três expressões se pressupondo e se implicando reciprocamente. É preciso que cada um dos três termos compreenda os dois outros. Que haja ao mesmo tempo uma necessidade absoluta entre eles; assim os três princípios de nosso ser - a vida, o espírito e a alma -, formam uma trindade. Por quê? É que a vida e o espírito são uma só e mesma alma; a alma e o espírito são uma só e mesma vida; a vida e a alma, um só e mesmo espírito (Delsarte, 20II, p.I7, tradução nossa)7.

O princípio da trindade é, portanto, uma formação constituída pela unidade de três elementos interdependentes, cada qual coexistindo no tempo com os demais, compenetrando-se no espaço e cooperando com o movimento. Shawn (2005) enumera algumas dessas trindades a título de ilustração: vida-alma-espírito, fazer-ser-ter, físico-emocional-mental, vital-espiritual-intelectual, sensível-moral-reflexivo. Para esse mesmo autor as trindades pressupõem o fato de um fenômeno possuir, portanto, um centro e duas extremidades opostas, o que levaria Delsarte, por questões metodológicas, a acrescentar a elas três aspectos qualitativos que caracterizariam a direção do fenômeno analisado, tal como: centrado (centro), excêntrico (do centro para periferia) e concêntrico (da periferia para o centro).

Tomados como critérios de organização, esses aspectos serão agregados ao esquema intitulado "Accord de neuvième" - ou acordo do nono -, desdobramento das tríades
Ce qui demande un volume est exprimé par un seul geste. Cent pages ne dises pas ce que qu 'un simple mouvement peut exprimer, parce qu'un simple mouvement exprime notre être tout en tier. (Delsarte apud Shaw, 2005, p. 72)

6 Em vida, os únicos documentos deixados por Delsarte foram o diagrama Compendium e os Archive du Chant. Reproduções de seus manuscritos podem ser encontradas nas obras de Alain Porte - François Delsarte, une anthologie - e de Angélique Arnaud - Fraçois Del Sarte: ses découvertes en esthétique sa science, sa méthode, além da já citada obra de Ted Shaw.

7 Le principe de mon système repose sur le constat qu'il y a dans le monde une formule universelle qui s'applique à toutes les sciences, à toutes les choses possibles. Cette formule est la trinité. Que faut-il pour former une trinité ? II faut trois expres sions se présupposant et s’impliquant réciproquement. Il faut que chacun des trois termes comprenne les deux autres. Qu'il $y$ ait en même temps conécessité absolue entre eux ainsi les trois principes de notre être, la vie, I'esprit et I'âme, forment une trinité. Pourquoi ? C'est que la vie et l'esprit sont une seule et même ame; I'âme et I'esprit sont une seule et même vie ; la vie et I'âme, un seul et même esprit. (Delsarte, 2011, p.17) 
em nove partes, que dará origem ao modelo de tabelas pedagógicas criado por Delsarte. A título ilustrativo, vejamos a seguinte matriz que explicita as relações propostas no “Accord de neuvième" e, em seguida, sua aplicação no que tange aos gestos de uma das muitas regiões do corpo analisadas pelo autor.

\begin{tabular}{|c|c|c|}
\hline $\begin{array}{c}\text { EXCÊNTRICO } \\
\text { Excêntrico }\end{array}$ & $\begin{array}{c}\text { NORMAL } \\
\text { Excêntrico }\end{array}$ & $\begin{array}{c}\text { CONCÊNTRICO } \\
\text { Excêntrico }\end{array}$ \\
\hline $\begin{array}{c}\text { EXCÊNTRICO } \\
\text { Normal }\end{array}$ & $\begin{array}{c}\text { NORMAL } \\
\text { Normal }\end{array}$ & $\begin{array}{c}\text { CONCÊNTRICO } \\
\text { Normal }\end{array}$ \\
\hline $\begin{array}{c}\text { EXCÊNTRICO } \\
\text { Concêntrico }\end{array}$ & $\begin{array}{c}\text { NORMAL } \\
\text { Concêntrico }\end{array}$ & $\begin{array}{c}\text { CONCÊNTRICO } \\
\text { Concêntrico }\end{array}$ \\
\hline
\end{tabular}

Figura 02 - Princípio do Accord de neuvième

Fonte: Shawn, 2005, p.70, adaptado pela autora, tradução nossa

A aplicação prática desse raciocínio em uma análise dos movimentos da cabeça seria:

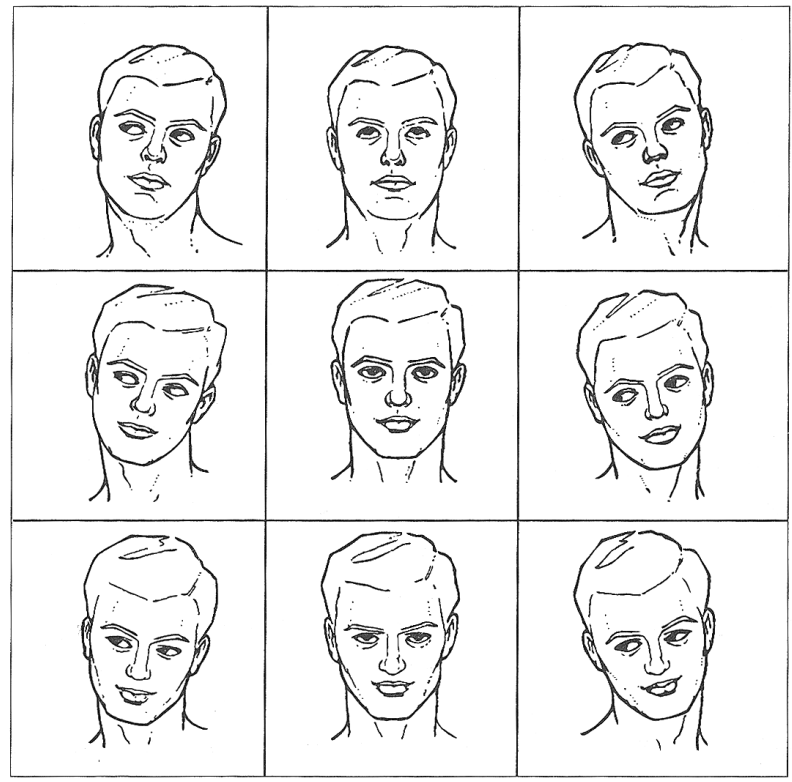

Figura 03 - Gestos da Cabeça - Fonte: Shawn, 2005, p.80

Na análise da imagem, em relação à tabela apresentada, teríamos, por exemplo, no primeiro quadrante, uma atitude excêntrica-excêntrica, na qual a cabeça está virada 
e elevada no sentido inverso a um suposto objeto ou pessoa o que, segundo as observações delsartistas, conota uma atitude de repulsão ou arrogância. Sucessivamente, cada uma dessas posições teria um significado associado. Dessa maneira, Delsarte foi desenvolvendo, minuciosamente, uma espécie de catálogo de gestos que envolvia a cabeça, os braços, as mãos, o torso, as pernas e suas respectivas posições e associações.

Ele elaborou ainda uma série com nove leis que governariam o movimento (altura, força, impulso, sequência, direção, forma, velocidade, reação e extensão); refletiu sobre o equilíbrio, a respiração, o ritmo, as ordens do movimento e fez a avaliação de inúmeras posturas humanas, buscando sempre compreender e revelar o que estava "por trás" delas. Como forma de esquematização de seu trabalho, Delsarte desenvolveu o Compendium $^{8}$, um diagrama que apresenta seu sistema de pensamento e que foi sendo aperfeiçoado ao longo de toda sua carreira.

Apesar de toda a investigação realizada e dos inúmeros cursos ministrados, Delsarte não deixou nenhuma obra publicada em vida. O delsartismo, que ganhou fortemente os domínios da expressividade do corpo humano, principalmente nos Estados Unidos, no final do século XIX e início do século XX, foi fruto da projeção do sistema por meio de discípulos de Delsarte, bem como seus seguidores.

Entre seus alunos destacou-se o ator americano Steele MacKaye (1842-1894), que, segundo Bourcier (200I), trabalhou com Delsarte em I869 e foi escolhido por ele como seu herdeiro espiritual. Para Suquet (2005), esse encontro potencializou fundamentalmente o acesso e a aproximação de áreas artísticas - entre elas a dança -, ao delsartismo. Isso porque, segundo a autora, o empreendimento de Delsarte jamais se voltou para a elaboração de um verdadeiro método de ensino, o que só aconteceu quando Mackaye elaborou a denominada ginástica harmônica, criada em princípio, para facilitar seu próprio aprendizado enquanto seguia o curso do seu mestre.

Mackaye afirmava que o princípio que o fizera assimilar rapidamente os gestos propostos por Delsarte foi uma análise aprofundada de seus próprios movimentos enquanto buscava articulá-los. Ele procurava estudar os obstáculos físicos que surgiam e dificultavam sua gesticulação, entendendo que isso se devia ao modo como seu corpo se organizava para realizar as ações que lhe eram propostas. Desse modo, começa a surgir uma cultura psico-física do movimento, que pode ser considerada o início de uma prática que daria origem as técnicas de análise do movimento.
$8 \mathrm{~A}$ imagem desse sistema de Delsarte está disponível em Macel; Lavigne, 2011, p.37. Uma cópia dele pode ser encontrada em Andrade, 2013 (tese de doutorado). Ver referências finais. 
9 Bourcier (2001) enumera as três principais escolas que teriam encaminhado o delsartismo à dança moderna. (1) Em Paris, Gustave Delsarte, filho de François Delsarte, ensina o método à Henriette Crane, que formou alunos nos Estados Unidos. Entre eles estava Mary Perring King, que transmite o ensinamento a Ted Shawn que, posteriormente, trabalhará com a própria Henriette Crane. (2) A professora de dança Geneviève Stebbins (1857-1933), uma discípula direta de Delsarte, passa a integrar os métodos em suas aulas e teria como aluna a bailarina Isadora Duncan. (3) Aurilla

Colcord Poté, aluna de MacKaye ensina o método à mãe de Ruth Saint-Denis que será, portanto, a predecessora da filha.

10 Delsarte est le maître de tous les principes de flexibilité et de légèreté du corps et il devrait recevoir des remerciements universels pour avoir brisé les chaînes qui entravaient nos membres. En complément à l'éducation en danse habituelle, sa méthode, si elle est enseignée avec fidélité, donnera des résultats exceptionnellement gracieux et charmants. (Duncan apud Shawn, 2005, p.142)
Vale lembrar que, segundo Suquet (2005), o período histórico em que o delsartismo tornou-se conhecido nos Estados Unidos - fim do século XIX - coincide com a segunda revolução industrial americana, em que o país estava mergulhado em um inédito e acelerado processo de racionalização tecnológica que se aplicava também às condições de vida e trabalho. Contrariando essa tendência de hipercivilização, os indivíduos passaram a questionar aqueles que seriam seus recursos físicos e espirituais primeiros e, assim, nos idos de I880, multiplicaram-se os movimentos que buscavam recriar "experiências autênticas" que permitissem ao indivíduo um encontro com ele mesmo. Sob essa nova orientação cultural, eclodem os movimentos esotéricos - a partir de I870 - pela busca da saúde, do desenvolvimento individual e social, ensejo no qual surgem inúmeros métodos de educação física e expressão. As práticas pedagógicas e as teorias da educação física foram revistas. Abandonou-se uma concepção militarista em prol de uma visão mais terapêutica que refletisse a condição corporal em um processo de transformação global, ou seja, considerando-se tanto os aspectos físicos quanto os psíquicos de cada sujeito.

Foi esse terreno fértil que Mackaye encontrou no retorno a seu país onde começou a aplicar e divulgar o método da ginástica harmônica que, rapidamente, alcançou sucesso entre os americanos.

\section{A Dança pós-Delsarte}

Isadora Duncan (I878-I927), Ruth Saint Denis (I880-I968) e Ted Shawn (I89II972) são importantes nomes, atrelados à criação da dança moderna americana e que, sabemos $^{9}$, experimentaram os métodos delsartistas. O mesmo Shawn (2005) relata a descoberta de uma preciosa entrevista de Isadora Duncan publicada em uma das primeiras revistas de dança americana, The Director, em que ela afirmava:

Delsarte é o mestre de todos os princípios de flexibilidade e de leveza do corpo e ele deveria receber o reconhecimento universal por ter rompido os encadeamentos que entravavam nossos membros. Em complemento à educação habitual em dança, seu método, se for ensinado com fidelidade, dará resultados excepcionalmente graciosos e charmosos (Duncan apud Shawn, 2005, p.I42, tradução nossa) ${ }^{10}$. 
Com o desejo movente de “dançar sua vida", suas paixões e emoções, Isadora rechaçou o modelo rígido e formal da dança vigente à sua época e encontrou na natureza a fonte de uma nova dança. Observando a harmonia do movimento das ondas, dos ventos e da terra, Duncan (20II) passou a questionar a natureza do movimento do homem que teria sido perdida diante da civilização. Em sua concepção, o movimento de todas as criaturas vivas estaria atrelado ao movimento universal e seria consequência do condensamento das forças maiores, que regem o próprio movimento da Terra. Nesse sentido, a dança seria simplesmente a gravitação desse movimento singular que ela denominava "volonte" II e que não seria nada mais que a própria tradução humana da gravitação do universo.

Foi a partir dessa compreensão do movimento que Duncan desaprovou as atividades da dança que estivessem em desacordo com a forma e o movimento da natureza, como era o caso das escolas de ballet que "lutavam contra" a lei da gravidade e desconsideravam as predisposições do indivíduo, produzindo movimentos que a bailarina chamava de estéreis. Ela criticou ainda os movimentos que não consideravam ações precedentes ou futuras, ou seja, que terminassem em si mesmos, sem continuidade ou sucessão. Baseada em questões como essa, Duncan reivindicou uma nova escola para a dança, preocupada que estava com a busca pelos movimentos fundamentais do ser humano.

Isadora presumia desde então uma dança futura que surgiria em consequência da evolução do ser humano, uma dança que libertaria o corpo feminino e reivindicaria não só um novo movimento, mas outra ideia de beleza, afastada do rígido compromisso da forma. Seus questionamentos e experimentações tornaram-na emblemática também como uma personalidade precedente ao movimento feminista, uma vez que nela já se manifestava o ideário da liberdade da mulher, haja vista, como revela Suquet (2006), que Duncan teria sido uma das primeiras bailarinas a abandonar o espartilho em direção a uma dança livre e às conquistas femininas que estavam por vir.

Aliás, a relevância que a dança passa a dar ao torso do corpo é destacada por Shawn (2005), lembrando-nos que, até então, o torso que permanecia estático passa a ganhar liberdade com artistas tais como Duncan. O corpo passa ainda a ser compreendido como um instrumento essencial de toda expressão emocional autêntica, e várias atividades e experimentações em dança passam a voltar-se para a conquista de sua mobilização. Em concordância, Bourcieur (200I) afirma que os bailarinos modernos consideram o torso como "a fonte e o motor do gesto (p. 245)".
11 Em francês, encontramos vários sinônimos para a palavra volonté, mas os que nos parecem mais adequados são: intenção, desejo, vontade. Por essa variedade de significados apreendidos pela palavra, optamos por deixá-la no formato original. 
12 No catálogo da exposição Danser sa vie (Macel; Lavigne, 2011), observa-se uma original preocupação de Duncan em relação à difusão da dança e à educação de jovens bailarinos. Ela teria realizado inúmeras turnês em países diversos e criado ainda escolas de dança na Alemanha, na França e na antiga URSS.
Nessa esteira, a americana Ruth Saint Denis, assim como Duncan, foi uma artista revolucionária no que diz respeito à emancipação do movimento dos maneirismos e artifícios do ballet do século XIX. Bourcier (200I) afirma que cabe a ela o título de the first lady of american dance (p. 253), uma vez que ela não só teria aprofundado as noções de Duncan como também criado um método que lhe tornou capaz de formar inúmeros alunos-discípulos. Também em Shawn (2005) encontramos a afirmação questionável ${ }^{12}$ de que, embora o impacto de Duncan sob a dança moderna seja incomensurável, ela não teria "feito escola” não tendo assim perpetuado sua obra, nem adquirido muitos seguidores. Ao contrário disso, Ruth Saint Denis e o próprio Ted Shawn, que se casaram em I9I4, fundaram a Denishaw School (I9I5-I93I) e uma companhia de mesmo nome. Com isso, teriam influenciado toda uma segunda geração de bailarinos modernos, formados durante os I7 anos de atividade da escola.

Para Suquet (2005), por vias distintas, Ruth Saint Denis e Ted Shawn atrelaram a religião à dança e sustentaram um viés terapêutico das técnicas delsartistas, o que se justifica facilmente quando analisamos alguns fatos da vida desses artistas. Ted Shawn procurou a dança para superar os efeitos reminiscentes de uma difteria que o afastou em definitivo da formação que seguia, na Universidade de Denver no Colorado, e que o tornaria pastor metodista. De modo semelhante, a mãe de Ruth Saint Denis, vítima de neurastenia, seguia o curso de Aurilla C. Poté que, por sua vez, fazia uso do delsartismo, no desenvolvimento de exercícios físicos que auxiliavam na superação de problemas nervosos. Abraçando os ensinamentos de Poté, a mãe de Ruth Saint Denis ensinará à filha essa dança que ela considerava uma aproximação suscetível entre corpo e alma, medicina e religião.

Nancy Lee Ruyter, no prefácio do mesmo livro de Shawn (2005), também afirma que o casal se interessava pela dança e religião sem, no entanto, privilegiar o cristianismo ocidental. Com essa fundamentação, o credo universal que seria potencializado na Denishawn School diz sobre o ecletismo e a exploração de estilos e entende que a dança é muito vasta para se aprisionar em um único sistema. O entendimento múltiplo da dança, apregoado pelo casal, propunha que as incontáveis maneiras de o homem se mover exprimem o nosso pertencimento ao universo e, portanto, todas as contribuições à dança são válidas, seja qual for a raça, a nacionalidade e a época em que o homem se move. 
Nesse contexto, retomemos as notáveis mudanças na concepção do corpo e do movimento na dança moderna que foram, em algum grau, herdadas do delsartismo. De acordo com Shawn (2005), outra grande diferença da dança do século XX, que surge, inicialmente, em decorrência de exercícios propostos por Mackaye, baseados na lei da reação ${ }^{13}$, está na atenção dada a atividades de tensão e relaxamento, que passam a ser utilizados de maneira consciente, rítmica, controlada e intencional. Essa experiência permite ao bailarino atingir maior qualidade na movimentação, que pode tornar-se mais fluida, natural e confortável. Associados às unidades de tempo e espaço, os princípios de tensão e de relaxamento garantirão, ainda, uma paleta dinâmica de movimentos com infinitas gradações de energia e fluxo.

Destaca-se, também, seguindo as proposições do mesmo autor, o reconhecimento do valor e da utilização da massa e do peso do corpo; da gravidade e de nossa relação com ela, como fontes de expressão. Delsarte estipulava que a velocidade do movimento era diretamente proporcional ao peso a ser deslocado e ao espaço a ser percorrido. Ele acreditava, assim, que o arranjo entre esses elementos é capaz de exprimir emoções distintas, de tal maneira que associava, por exemplo, emoções profundas a movimentos lentos e amplos; emoções pequenas ou superficiais a movimentos curtos e vívidos.

Com as proposições de Delsarte e com a astúcia e ousadia de seus seguidores, a dança realizara um salto sobre si mesma. Atentando-se para outras possibilidade e potências do corpo sensível como um todo, entram no “jogo do movimento" novos elementos com capacidade exponencial de combinação que irão definitiva e irreversivelmente alterar o vocabulário da dança. Assim, devemos concordar com a afirmação de Suquet (2005) que faz jus à verdadeira revolução que atingiu a linguagem da dança pós-Delsarte, por trás da qual, podemos afirmar, estava a velha batalha humana de juntar o que Descartes separou, ou seja, o corpo e a alma:

Os pioneiros da dança moderna americana foram, verdadeiramente, banhados no delsartismo. O cruzamento entre medicina, psicologia e arte contribuiu de maneira capital na transformação da visão da relação entre corpo e espírito, favorecendo o nascimento de uma nova prática do movimento que constitui o fundamento da dança moderna. (Suquet, 2005, p.3I, tradução nossa) $)^{14}$

Certamente, essas novas práticas do movimento não se restringiam ao território norte- americano. Na Alemanha, essa verdadeira revolução do movimento também
13 A lei de reação: qualquer objeto que surpreende, tenha ele um aspecto agradável ou desagradável, faz o corpo reagir de volta. O grau de reação é proporcional ao grau de emoção provocada pela visão do objeto. Qualquer emoção extrema tende ao seu oposto: a concentração passional tende à explosão, a explosão tende à prostração. A única emoção que não tende a sua própria destruição é aquela que é perfeitamente controlada, temperada e equilibrada. (Shawn, 2005, p. 97-98, tradução nossa)

14 Les pionniers de la danse moderne américaine ont véritablement baigné dans le delsartisme. Au croisement entremédicine, psychologie et art, celui-ci a contribué de manière capitale à transformer la vision du rapport entre corps et esprit, favorisant la naissance d'une nouvelle pratique du mouvement qui constitue le fondement de la danse moderne. (Suquet, 2005, p.37) 
15 Apesar de Laban ter estudado com um discípulo de Delsarte, Shawn (2005) afirma que a origem do movimento da dança moderna alemã está atrelada à permanência de Isadora Duncan e Ruth Saint Denis no país - que por lá dançaram e ensinaram durante alguns anos. Porém, como sabemos, a opinião de Shawn a esse respeito parece contaminada pelo desejo de valorizar a influência de Delsarte sobre a dança moderna, de maneira generalista.

16 Para o mesmo propósito, também encontramos na literatura consultada a nomenclatura: Eurritmia (Azevedo, 2009), Euritmia (Strazzacappa, 2012) e, em francês, eurythmique

(Macel, 2011).

17 Harmonie d'ordre supérieur. (Macel, 2011, p.23) estava em vigor, sendo que os primeiros nomes da dança moderna teriam sido Rudolf Von Laban (I879-I958) ${ }^{15}$ e Mary Wigman (I886-I973), sua mais renomada aluna. Porém, antes de abordarmos tais personagens iremos destacar outra figura comprometida com o novo pensamento do corpo e da dança e que também atuou na Alemanha: Émile Jacques Dalcroze (I865-1950).

\section{O canto do tônus}

Dalcroze foi um musicista e pedagogo suíço que acreditava no aprendizado do ritmo por meio do movimento do corpo. Para Bourcieur (200I), ele compreendia o corpo como um ponto de passagem obrigatório entre o pensamento e a música, o que o fez acreditar que o movimento poderia ditar ritmo ao pensamento. Com base nesse princípio, Dalcroze elaborou sua pedagogia do movimento baseado na Rítmica ${ }^{\mathrm{I}}$, um treinamento da sensibilidade musical, baseado no movimento corporal, que entendia o ritmo como uma linguagem primária do homem. Seu método tornou-se célebre, não só no universo da música, como no teatro e na dança.

Ribeiro (20II) nos explica que a Rítmica de Dalcroze é constituída pela ginástica rítmica, pelo solfejo e pela improvisação, tendo a plástica animada como consequência estética das práticas de seu sistema. O aluno de ginástica rítmica, como descreve Macel (20II), devia seguir a cadência de uma improvisação ao piano, realizando movimentos do corpo em acordo com a música. Em seguida, ele era levado a solfejar e cantar, também de maneira improvisada. De tal forma, era exercitada a harmonia entre o ritmo e o movimento do corpo, que seriam, então, expressos pelos gestos. Não por coincidência, esse princípio nos faz lembrar Delsarte, de quem Dalcroze herdou a trindade corpoalma-espírito como fundamento de seu sistema.

Nesse sentido, as faculdades corporais e espirituais do corpo estariam unidas e teriam um ideal comum, uma "harmonia de ordem superior" (Macel, 20II, p. 23, tradução nossa) $)^{17}$ que estaria na rítmica - enquanto agente de ligação entre corpo e alma. O que Dalcroze buscava investigar era, então, esse agente que oferecia a possibilidade de revelação, no domínio físico, das vibrações engendradas pelas emoções mais elementares dos seres humanos. Se a rítmica era responsável por esse fenômeno, o gesto era sua própria expressão. 
Assim como Delsarte, Dalcroze acreditava que os gestos seriam a tradução direta de nossas emoções por via do movimento do corpo, uma espécie de exteriorização do espírito e espiritualização da matéria. Para ele, haveria uma equivalência entre cada gesto e um signo musical, e a essa dimensão acrescentou as propriedades estéticas do gesto que poderiam ser alcançadas pelo corpo dentro da crença de que "Uma vez o corpo musicalizado e impregnado de ritmos e nuances, a plástica animada torna-se pouco a pouco uma arte superior sendo suficiente por si mesma" (Dalcroze ${ }^{18}$, 1916, p.36 apud Macel; Lavigne, 2011, p. 50, tradução nossa) $)^{19}$.

Portanto, a plástica animada diz respeito à dimensão estética do gesto que, por meio da rítmica, poderia ser apreendida pelo corpo de maneira consciente, o que garante ao sujeito uma nova relação com sua própria gestualidade. Isso porque, uma vez que há o entendimento das nuances do ritmo e dos movimentos executados, também se abre a possibilidade de melhor controlá-los e executá-los.

Como nos lembra Louppe (2000), a maior descoberta de Dalcroze consistia em sua compreensão de que as próprias modulações do tecido muscular compunham nossa relação com o simbólico, com o tempo e com o espaço, promovendo assim nossas ferramentas de expressão. Conforme a mesma autora, esse modo de sensibilidade, coloca o corpo entre dois vetores - a nosso ver justapostos -, aquele do desejo interminável ao que nos parece externo e nos faz mover e aquele da imediata transposição rítmica do que seria uma "vida interior" em descargas corporais.

Ao que nos parece, o exercício da rítmica pretendia promover, assim, uma relação harmônica entre o desejo do movimento e o de expressão, vislumbrados, sentidos, permeados e revelados no corpo, acordes que são urgências da dança, ou seja, é da ordem do desejo do bailarino saber exercer o controle e a manipulação gestual como garantia de uma qualidade de movimento. Assim, não é de se surpreender que a afinidade das aspirações dalcrozianas com a dança tenha promovido o encontro entre esses dois campos.

No entanto, Dalcroze difere, claramente, sua plástica animada - que seria uma espécie de música corporificada -, da dança. Para ele, a dança, embora pudesse alcançar a graciosidade do movimento, era uma atividade superficial, que deveria se aproximar da música e mais precisamente do ritmo para que assim, e somente assim, seus movimentos se tornassem verdadeiramente artísticos e expressivos. Só o controle do ritmo daria ao bailarino a possibilidade de refinamento na execução de seus movimentos e, por

18 Dalcroze, Émile Jacques. Méthode Jacques-Dalcroze. Exercices de plastique animée, V.1, Lausane Jobin \& Cie, 1916, p.36.

19 Une fois le corps musicalisé et imprégné de rythmes et de nuances, la plastique animée redeviendra peu à peu un art supérieur se suffisant à lui-même. (Dalcroze, 1916 p.36) 
isso, o corpo plástico precisava estar sempre atrelado ao ritmo musical, em uma unidade global. Essa unidade estaria presente na rítmica, a partir da qual - ao contrário do que se disse sobre a dança -, seriam cultivados, em conjunto, a mente, o corpo e o espírito.

Assim, segundo Suquet (2006), a pedagogia dalcroziana foi relevante na formação de uma geração da dança moderna alemã, no que tange ao estímulo à investigação da natureza da percepção do movimento. Os questionamentos de Dalcroze - como a crença de que a fonte do movimento estaria em uma contínua troca de fluxos físicos e em suas repercussões sensoriais -, dirigem-se, precisamente, ao sentido interior do movimento, à investigação sobre as sensações do movimento e suas possibilidades, fatores que vão ao encontro da dança. No entanto, o pensamento divergente entre a dança e a plástica animada custou a Dalcroze alguns rompimentos.

Como marco desses rompimentos entre campos, citamos Wigman, considerada uma das fundadoras da dança expressionista alemã e que estudou no Instituto Dalcroze de Hellerau ${ }^{20}$. O encontro da bailarina com a pedagogia dalcroziana parece ter sido breve, uma vez que Wigman, embora tenha feito uso dos princípios que conheceu, não

20 Distrito de Dresden no leste da Alemanda, no qual Dalcroze fundou o Instituto Educativo de Ginástica Rítmica.

21 Suzanne de Perrottet (1889-1983), que foi aluna e depois professora de ginástica rítmica, também divergiu de seu mestre no que se refere às concepções sobre música e movimento. Wigman, Perrottet,

Mary Rambert e Annie Beck começaram a estudar o movimento dissociado da música. se deu por contente pela maneira como a dança em Dalcroze parecia, no ponto de vista da bailarina, subjugada em relação à música. Com algumas parceiras ${ }^{21}$ de insatisfação, Wigman começou a experimentar o movimento desvinculado da música, experiência que ganhou potência no encontro com Laban que, embora também tenha recebido influências dalcrozianas e até mesmo frequentado os festivais que aconteciam em Hellerau, promoveu essa desvinculação entre corpo e música, acreditando que o corpo era capaz de produzir livremente seu próprio ritmo.

Estava traçado o caminho inicial para outra mudança de cenário na dança que ainda hoje se faz vigente. Como aponta Louppe (2000), houve um deslocamento da problemática gestual na dança em que o bailarino deixa de procurar a música que vai além de seu gesto e volta-se para o próprio gesto, a fim de descobrir o “chant du tônus" (Louppe, 2000, p.I6o) - ou, canto do tônus -, o ritmo do corpo, suas colorações e variações tônicas. O princípio dessa variação tônica teve então sua revelação originária em Dalcroze, visto que foi ele quem investigou, inicialmente, o ritmo como pulsação de vida revelada em nuances musculares e, dessa forma, para Louppe, teria descoberto a dança:

Dalcroze compreende então que a nuance está em nós: é o aumento ou a diminuição da textura muscular ou nervosa, que à menor crispação, a qualquer ação emotiva executada, 
faz vibrar ou desmanchar. E tudo isso faz sentido. E tudo isso compõe. Há então, um canto interior que é esse do tônus (Louppe, 2000, p.I6o, tradução nossa) ${ }^{22}$.

A mutação do tônus é para Dalcroze a linguagem poética primeira do corpo. Seria essa a maior contribuição do pedagogo para a dança e também para as ciências nas quais essa noção seria retomada. Será também essa a recuperação feita por Laban no desenvolvimento de sua teoria, embora, como afirma Louppe, ele não tenha preocupado em mencionar suas fontes.

Laban e Wigman se conheceram em I9I3 no Monte Veritá - uma espécie de comunidade utópica que se formou aos pés da colina que lhe deu nome, próximo a uma vila Suíça denominada Ascona. Nesse território múltiplo e libertário, Laban põe à prova suas primeiras tentativas de tornar livre e, ao mesmo tempo expressivo, o movimento do corpo que dança. Aos seus alunos, entre eles Wigman, ele propõe uma investigação sobre as obscuras fontes emocionais do movimento que, quando acessadas, acreditavase, poderiam promover e transmitir uma experiência existencial de mundo. Para tanto, seus ensinamentos voltam-se para a percepção sensorial do tempo, da energia e do espaço, que seriam elementos fundamentais para que a dança alcançasse uma experiência intensa de movimentação em relação ao mundo.

Laban e Wigman abriram uma escola em Zurique entre I9I7 e I9I8 e tornaram-se figuras complementares e edificadoras da dança alemã - ele, pelo pensamento visionário; ela, pela nova e emblemática estética que alcançara. A edificação teórica, que seria a maior herança de Laban para a dança, surge tempos depois do Monte Veritá, ainda que carregue consigo as reflexões lá iniciadas.
22 Dalcroze comprend

donc que la nuance est en nous: c'est l'augmentation ou la diminution de la texture musculaire et nerveuse, que la moindre crispation, le moindre passage émotif travaille, fait vibrer, ou effondre. Et tout cela fait sens. Et tout cela compose. Il y a donc un chant intérieur qui est celui du tonus. (LOUPPE, 2000, p.160) 


\section{Referências}

ANDRADE, Graziela Corrêa de. Corpografia em dança: da experiência do corpo sensivel entre a informação e a gestualidade. Tese (doutorado em...) - Escola de Ciência da Informação, Universidade Federal de Minas Gerais, 20I3.

AZEVEDO, Sônia Machado. O papel do corpo no corpo do ator. São Paulo: Perspectiva, 2009.

BOURCIER, Paul. História da Dança no Ocidente. São Paulo: Martins Fontes, 200I.

COURTINE, Jean-Jacques. Histoire du corps. Le XX $X^{\circ}$ siècle. Paris: Éditions du Seuil, 2006. (V.3 Les mutations du regard)

DELSARTE, François. Cours d'esthétique apliquée (extrait des cahiers d'étudiants). In : MACEL, Christine; LAVIGNE, Emma. (Org.). Danser sa vie: écrits sur la danse. Paris: Éditions du Centre Pompidou, 2011, p.17-19.

DUNCAN, Isadora. La Danse de l'avenir. In: MACEL, Christine; LAVIGNE, Emma. (Org.). Danser sa vie: écrits sur la danse. Paris: Éditions du Centre Pompidou, 2011, p. 35-41.

LOUPPE, Laurence. Corpos Hîbridos in Lições de Dança. 2. ed. Rio de Janeiro: Ed. UniverCidade, 2000.

MACEL, Christine. Anna Halprin.In:MACEL, Christine; LAVIGNE, Emma. (Org.). Danser sa vie: art et danse de I900 à nous jour. (Catálogo). Paris: Éditions du Centre Pompidou, 20II, p. 242-245.

MACEL, Christine; LAVIGNE, Emma (Org.). Danser sa vie: art et danse de I9oo à nous jour. (Catálogo). Paris: Éditions du Centre Pompidou, 2orI.

RIBEIRO, Mônica Medeiros. Dalcroze e a dança moderna: indícios de uma presença. In: REUNIÃO CIENTÍFICA ASSOCIAÇÃO BRASILEIRA DE PESQUISA E PÓS-GRADUAÇÃO EM ARTES CÊNICAS - ABRACE, 6., 2OII, Porto Alegre, 20II.

SHAWN, Ted. Chaque petit mouvement. À propos de François Delsarte. Paris: Éditions Complexe et Centre Nacional de la danse, 2005 .

STRAZZACAPPA, Márcia. Educação somática e artes cênicas: princípios e aplicações. Campinas: Papirus, 2012.

SUQUET, Annie. Introduction. In: SWAWN, Ted. Chaque petit mouvement. À propos de François Delsarte. Paris: Editions Complexe et Centre Nacional de la danse, 2005, p. 2I-34.

SUQUET, Annie. Scènes Le corps dansant: un laboratoire de la perception. In: COURTINE, JeanJacques. Histoire du corps. Le XXffl siècle.Paris, Éditions du Seuil, 2006, p. 407-429. (V.3 Les mutations du regard). 
